\title{
LA HIPÓTESIS DE LA LIBERTAD FRENTE AL DESAFÍO DE LA NEUROCIENCIA*
}

\author{
Adrian Sgarbi \\ Pontifícia Universidade Católica do Rio de Janeiro (PUC-Rio) \\ Cátedra de Cultura Jurídica, Universitat de Girona (UdG)
}

RESUMEN. El tema de la libertad en los tribunales de justicia, al menos en el contexto norteamericano, es tratado como una hipótesis de trabajo, la cual primero fue cuestionada por la filosofía, y defendida en su alcance jurídico por teóricos y filósofos del derecho. Sin embargo, en los últimos años está emergiendo un nuevo frente de incertidumbre en relación con la conducta de la libertad humana; esta vez desde los neurocientíficos. Entendemos por neuroderecho el campo del conocimiento cuyo objetivo consiste en explorar los hallazgos de la justicia neurocientífica. Este estudio presenta el tema de la libertad en el contexto de los tribunales de justicia en su cuestionable aplicación de las formulaciones neurocientíficas, para delimitar el alcance de su uso.

Palabras clave: libertad, responsabilidad, neuroderecho.

\section{The Free Will Hypothesis against the Challenge of Neuroscience}

ABSTRACT. The topic of freedom in the legal courts, at least in the North American context, is treated as a working hypothesis, which was first questioned by philosophy, and defended in the legal scope by theorists and philosophers of law. However, in recent years a new front of uncertainty is emerging, regarding the conduct of human freedom; this time through the neural-scientists. Under neurolaw we understand the field of knowledge which purpose is to explore the findings of neural-scientific justice. This study presents the theme of freedom in the context of the courts of justice in their questionable application of neural-scientific formulations, in order to delimit the extent of their use.

Keywords: free will, responsibility, neurolaw.

\footnotetext{
* Fecha de recepción: 25 de junio de 2013. Fecha de aceptación: 31 de octubre de 2013.

Este trabajo fue realizado en el marco del proyecto DER2010-21331-C02-02, del Ministerio de Ciencia e Innovación (España) y conforme al acuerdo celebrado entre la Universidad de Girona y la Pontifícia Universidade Católica de Rio de Janeiro, Brasil. Me gustaría expresar mi agradecimiento a los profesores J. FERRER, M. Narváez, D. Papayannis, N. Muffato, M. Atienza, J. Ruiz Manero, D. GonZález Lagier, J. Valenzuela, D. CANALE y G. TuZET por las observaciones hechas, por la paciencia con los accidentes de mi castellano y por su amistad.
} 


\section{INTRODUCCIÓN}

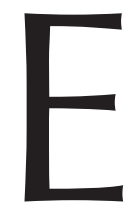

n relación con el caso de Steward Mach. Co. vs. Davis, el juez Benjamin Nathan Cardozo afirmó que: «Hasta el momento, el derecho ha sido orientado por un fuerte sentido común que asume la libertad de la voluntad como una hipótesis de trabajo en la solución de los problemas jurídicos» ${ }^{1}$.

Dicha hipótesis, que ya había sido defendida cuando apenas se circunscribía a reflexiones filosóficas acerca de la responsabilidad humana ${ }^{2}$, parece recibir ahora un nuevo frente de consideraciones. Esto se debe a que la neurociencia aparece en los discursos de los tribunales para poner en cuestión la existencia de la libertad humana, ya sea en casos que involucran el derecho civil o el derecho penal ${ }^{3}$. En los medios de comunicación ${ }^{4}$, con mayor o menor amplitud, los especialistas han difundido todo tipo de experimentos y los han presentado acompañados de gráficos, opiniones técnicas y nuevas máquinas a través de las cuales, ellos afirman, se demuestra lo que di$\operatorname{cen}^{5}$. Actualmente, el uso judicial de algunas de estas técnicas y su poca sostenibilidad en muchas situaciones ha sido enfatizado, a su vez, especialmente, en el contexto de la prueba judicial (y de la duda razonable) ${ }^{6}$.

En este sentido, se puede decir que el tema del libre albedrío ha sido considerado, aunque no siempre con claridad, en tres niveles distintos: a) como una cuestión descriptiva; $b$ ) como una cuestión sustantiva, y c) como una cuestión prescriptiva. En el primer plano se pregunta qué es lo de qué se trata cuando se habla del libre albedrío; en el segundo plano, lo que importa saber es si los seres humanos poseen o no esta característica de libre albedrío; en el tercer plano, la pregunta involucrada es qué debemos hacer con este conocimiento [3-5].

Este artículo ofrece un análisis de la problemática relación entre estos tres niveles, comenzando por una crítica de ciertas posturas descriptivas. Al final, se sugiere que las descripciones aisladas, ya sea en el campo neurocientífico, o en el campo filosófico, han llevado a un callejón sin salida, cuyo efecto es la aseveración de que la libertad del comportamiento humano es una ilusión, y el libre albedrío, un gran misterio [6]. En conclusión, se presentan tres ajustes al debate para que éste no sólo sea inteligible en el ámbito jurídico [7], sino también provechoso para el uso de los avances del neuroderecho (neurolaw), circunscribiéndolo [8].

1 U.S. Supreme Court, Chas. C. Steward Mach. C. vs. Davis, 301 U.S. 548 (1937).

2 HART, 1958; Ross, 1975; SANTIAGO NinO, 1980.

3 Vid. el item 6 de este estudio y también: Entertainment Software Ass'n. vs. Blagojevich, 404 F. Supp. 2d 1051 (N.D. Ill. 2005) (caso «videojuegos violentos»); Fini vs. General Motors Corp, núm. 227592, 2003 Mich. App. Lexis 884 (Mich. Ct. App. Apr. 8 2003) (caso «daños cerebrales después de un accidente y su indemnización»); People vs. Weinstein, 591 N.Y.S.2d 715 (N.Y. Sup. Ct. 1992) (caso «deformación cerebral y acto violento»); People vs. Goldstein, 786 N.Y.S.2d 428 (N.Y. Sup. Ct. 2004) (caso «enfermedad mental de un agente que ha empujado a una mujer a los rieles del metro causando su muerte»).

${ }_{4}^{4}$ Kershaw, 2002; Gazzaniga; Steven, 2005; Liptak, 2005; Lane, 2005; Overbye, 2007; Rosen, 2007; SAUL, 2008; HotZ, 2009; LipTAK, 2010; EAGLEMAN, 2011.

5 fMRI o funcional MRI (Functional Magnetic Resonance Imaging), por ejemplo, se hizo recurrente en casos que involucran la pena de muerte. Goodenough; Prehn, 2004; ChORVAT; MACCABE, 2004; SinNotARMSTRONG; ROSKIES; BROWN; MURPHY, 2008.

6 SCHAUER, 2010a. 


\section{1. ¿PERSONAS COMO ORDENADORES?}

Cuando enciendo mi ordenador cada pieza que lo compone desempeña una función. Él contiene muchos componentes y cada uno de ellos cumple una determinada tarea. En el supuesto caso de que alguno de estos componentes no esté funcionando perfectamente, mi ordenador no podrá desarrollar bien lo que yo espero al ejecutar un programa. Siendo así, al encender mi ordenador y no obtener ninguna respuesta, apenas se constata que la situación de frustración en relación a la imposibilidad de su uso era inevitable por las insuficientes condiciones físicas de la máquina.

Con el término «determinismo» se designa la tesis según la cual todo evento es provocado por eventos anteriores, considerando que ellos están regidos por las leyes de la naturaleza ${ }^{7}$. Se dice, asimismo, que un hecho está causalmente regido por los hechos anteriores, así como por las leyes de la naturaleza, cuando esos acontecimientos no pueden dejar de ocurrir sin violar leyes físicas o sin que hechos anteriores diferentes hayan ocurrido.

Sin embargo, a pesar de que esta afirmación sea relativamente simple, la noción de causalidad se ha expandido en los últimos años con el objetivo de alcanzar fenómenos relativos a la propia formación fisiológica de los seres humanos y a sus causas psíquicas. Esto se debe al hecho de que la ciencia contemporánea reconoce la existencia de factores intrínsecos a la mente humana y a la herencia genética, como también al medio ambiente, que pueden influenciar en la manera de reacción del ser humano ${ }^{8}$. A partir de la exacerbación de estas afirmaciones, dos argumentos empezarán a ser más frecuentes: el argumento de 1) «la causalidad a distancia» y el argumento de 2) «la inevitabilidad»?.

Conforme al argumento de la «causalidad a distancia» la acción de los agentes es sólo un reflejo de condicionamientos genéticos (determinismo genético). Se sostiene así que las acciones humanas son tan libres como la acción de un ordenador que cumple las especificaciones de «fábrica», es decir, las mismas provienen de programaciones biológicas que pueden presentar defectos y son previsibles ${ }^{10}$.

Según el argumento de la «inevitabilidad», los seres humanos son considerados meramente como seres reactivos en términos de sus capacidades psíquicas (determinismo psicológico). Siendo así, un cleptómano reacciona de acuerdo con su situación peculiar, que le impulsa a hurtar; quien sufre de una compulsión psicológica intrusiva realiza repetidas veces el mismo acto; el niño maltratado apenas puede volverse un agente peligroso al llegar a ser adulto; y en ninguno de esos casos tiene mucho sentido considerar libre la reacción, de modo que ellos apenas hacen lo que pueden hacer ${ }^{11}$.

Como es posible notar, la noción de determinismo parece poner en duda la libertad humana y, en último análisis, la propia utilidad de las normas. Esto se debe a que, como los seres humanos hacen parte del mundo natural, siempre se podrá preguntar: si todos los fenómenos ocurren necesariamente, ¿será que hay algún margen para ac-

\footnotetext{
7 WEATHERFORD, 2005.

8 NiNO, 1980: 367-368; SOBER, 2004: 67-74.

9 Ibid., 368-369.

10 SOBER, 2004: 73-74.

11 Ibid., 74; FERRAZ Jr., 1980: 99-105.
} 
ciones libres? ¿Los seres humanos son esclavos del determinismo? ¿Esto significa que no existe libertad (posible)?

Estas cuestiones están lejos de ser nuevas, asimismo, continúan despertando perplejidad. El porqué de ellas, sencillamente, parece derivar de que los hombres no pueden ser libres ${ }^{12}$.

Estas son las dos proposiciones relacionadas en el debate:

(PD) Proposición Determinista: «Todas las acciones tienen causas que las determinan».

(PL) Proposición de la Libertad: «Hay al menos algunas acciones para las que somos libres».

A partir de estas proposiciones, dos tipos de teorías buscan contestar al problema de la libertad: a) el incompatibilismo, y $b$ ) el compatibilismo. Por un lado, los incompatibilistas defienden que el enunciado «Todas las acciones poseen causas que las determinan» es inconciliable con el enunciado «Hay al menos algunas acciones para las que somos libres»; por otro lado, los compatibilistas afirman que los mismos enunciados son conciliables e intentan defender esta tesis.

Según la proposición elemental del incompatibilismo, los enunciados PD y PL son inconciliables, de modo que ambos son mutuamente excluyentes y conjuntamente exhaustivos. Sin embargo, los teóricos incompatibilistas no forman una única línea de pensamiento con respecto a las consecuencias de aceptar esa imposibilidad de convivencia ${ }^{13}$. De ahí la diferencia entre:

(1) Teóricos incompatibilistas «radicales» (hard determinism); y

(2) Teóricos incompatibilistas «liberales» ${ }^{14}$.

Para los «incompatibilistas radicales» (1), de la verdad de la primera proposición se deriva que carecemos de cualquier libertad. Por tanto, ellos son llamados «hard determinists» porque aunque eso sea difícil de aceptar, la verdad es que la libertad es una ilusión resultante de una equivocada proyección subjetiva humana; el hombre no está, realmente, dotado de ninguna voluntad libre porque sus decisiones están determinadas. Es decir, que:

Si PD, entonces no-PL

PD

Por tanto, no-PL

En cambio, para el «liberalismo» (2) es el segundo enunciado, PL, que es verdadero. En estos términos:

Si PD, entonces no-PL

PL

Por tanto, no-PD

12 De CARO, 1998: 167-195.

13 Kane, 1996; O'Connor, 2000.

${ }^{14}$ Uso el término de forma restrictiva al contexto de este trabajo y sin ninguna connotación propia de la filosofía política. 
La tesis central del liberalismo es que sólo es posible que haya libertad en un ambiente indeterminista ${ }^{15}$. Según entienden sus defensores, ese ambiente indeterminista se encuentra en alguna parte de nuestra construcción cerebral que posibilita voluntades y acciones autoformadas, las SFA's (self-forming actions) ${ }^{16}$. Dichas voluntades y acciones autoformadas son las que constituyen nuestro carácter y motivos, convirtiéndonos en lo que somos ${ }^{17}$.

Apartándose de estos contrastes, lo que más importa es que ambas formulaciones «incompatibilistas» poseen en común la concordancia con la afirmación de ser inconciliables PD y PL. Porque ser «incompatibilista» es defender la tesis de la imposible convivencia entre la «libertad» y el «determinismo». Asimismo, mientras el «incompatibilismo radical» afirma esta incompatibilidad para negar la libertad, el «liberalismo» afirma esta incompatibilidad para negar el propio determinismo en nuestras decisiones.

El problema es que si la libertad y el determinismo parecen ser incompatibles, lo mismo puede decirse con respecto al binomio libertad/indeterminismo. Porque decir que las decisiones tomadas por nuestro cerebro son consecuencias de eventos indeterminados es lo mismo que decir que la libertad afirmada y nuestros objetivos se fundan en una falta de control sobre nuestras decisiones y acciones o está constituida por efectos aleatorios, de modo que nuestras elecciones serían seleccionadas, al fin, sin relación con objetivos u opiniones. En otras palabras, «si la elección carece de causas se convierte en un acto irracional» ${ }^{18}$. En este sentido, el proverbio «el enemigo de mi enemigo es mi amigo» no es verdadero en todas las situaciones.

Como se desprende de lo dicho, contra el incompatibilismo, y como salida para el indeterminismo, se ha defendido la tesis de que el determinismo no excluye el enunciado de la libertad. Esta tesis es designada «compatibilismo» (compatibilism). Para el compatibilismo, a pesar de que el enunciado PD sea verdadero (es decir, aunque todas las acciones estén determinadas causalmente) nada impide que seamos libres: es decir, también PL puede ser un enunciado verdadero ${ }^{19}$. Por tanto, según el compatibilismo, la proposición determinista y la proposición de la libertad son ambas verdaderas.

Esto significa que el determinismo es verdadero, pero podemos actuar con libertad; las acciones humanas son libres y al mismo tiempo causalmente determinadas. Para el compatibilismo la libertad no exige la falsedad del determinismo causal. Y afirma esto, en último análisis, señalando que el choque entre la libertad y el determinismo es sólo aparente. Para poder explicarlo, los compatibilistas afirman que se debe indagar «lo que se entiende por libertad» ${ }^{20}$. Es decir, ellos no se atreven a negar la verdad del enunciado PD y la importancia de la comprensión de la causalidad física, psicológica o genética. Lo que hay que destacar es el refinamiento del segundo enunciado, refinamiento del enunciado PL. Procediendo así, el compatibilismo no sólo niega el incompatibilismo en todas sus formas, sea en la forma del «liberalismo», sea en la forma del hard determinism, sino que también asume la tarea de comprobar aquello que afirma.

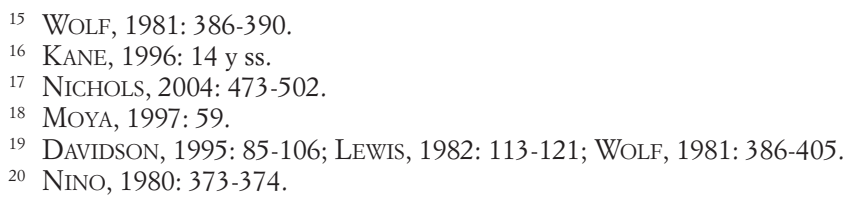




\section{CONCEPTO DE «SER» LIBRE}

Sobre la base de los problemas anteriormente citados, conforme se ha referido, la estrategia compatibilista consiste en proponer una reformulación del enunciado de la libertad para que evidencie los engaños del incompatibilismo. A partir de ahora, expondré esta estrategia a través de la explicitación de dos condiciones frecuentemente presentadas por los compatibilistas como «las condiciones de la libertad»:

a) la condición de la «autodeterminación» del agente; y

b) la condición de «alternativas» o de las «posibilidades empíricas de elegir».

\subsection{La condición de la autodeterminación del agente}

Todos los días realizamos una serie de previsiones sobre lo que va a ocurrir basándonos en la experiencia: al colocar algunas cucharadas de azúcar en el café, éste se «endulza»; al proyectar nuestras piernas hacia adelante entramos en «movimiento»; al beber agua «satisfacemos» nuestra sed, etc.; la implicación obvia de esas experiencias es la de confiar en que algo funcione o funcionará como ya ocurrió en el pasado y apoyamos esa impresión en la noción que generalmente poseemos sobre la causalidad. Otro ejemplo es el control a través de reprimendas a algunos comportamientos, como también los elogios dirigidos a las conductas aprobadas en el derecho ${ }^{21}$. Creemos que ellos tienen alguna utilidad porque les atribuimos alguna eficiencia en términos de provocar cambios en el mundo.

Con el objetivo de explicar todo esto salvaguardando el campo de la libertad, los compatibilistas sustentan la exigencia de la autonomía (o capacidad de autodeterminación del individuo) como primera condición para definir a alguien como libre. Según esta exigencia, el agente actúa libremente sólo cuando sus acciones no están determinadas exclusivamente por factores ajenos a su voluntad, sean estos factores genéticos o fisiológicos de alguna naturaleza.

Así, para H. FRANKFURT, la cuestión de la autodeterminación se resuelve mediante una jerarquía de voluntad. Su construcción es compatibilista porque entiende que su teoría posibilita identificar una voluntad libre que tiene sentido delante del determinismo ${ }^{22}$.

La diferencia entre los seres humanos y los demás mamíferos (FRANKFURT los denomina «mamíferos inferiores») es que los seres humanos son capaces de tener deseos sobre deseos (o metapreferencias) ${ }^{23}$. A esos estados mentales complejos FRANKFURT los llama «deseos de segundo orden». Por ejemplo, todos los días yo deseo comer tortillas de patatas. Este es mi deseo de primer orden. Aunque eso sea verdad, yo también deseo no tener el deseo de comer tortillas de patatas todos los días porque comiendo tortillas de patatas todos los días estoy engordando. El segundo deseo puede ser tra-

21 KeLSEN, 1957: 231; BOBBIO, 1977: 33-42.

22 FranKFuRT, 1971: 9-10.

23 Para un enfoque que incluye el factor tiempo en el análisis («plan de vida», «deseos» e «intereses») de las metapreferencias, BAYON, 1991: cap. 4. 
ducido en «yo no quiero desear comer tortillas de patatas o tantas tortillas de patatas todos los días».

Según FRANKFURT, los animales menos sofisticados que los seres humanos pueden tener deseos de primer orden, pero no deseos de segundo orden. Un perro puede desear comer carne, y, por tanto, es capaz de sentir deseos de primer orden. Sin embargo, él, el perro, no es capaz de desear no comer carne todos los días. Él no es capaz de tener deseos de segundo orden, de reflexionar con respecto al deseo inicial y negarlos, si es ese el caso ${ }^{24}$.

Los deseos de segundo orden, pueden asumir versiones distintas ${ }^{25}$ :

1. La primera de ellas es no querer tener el deseo que se tuvo inicialmente. Aquí tenemos otra vez el ejemplo de las tortillas de patatas.

2. La segunda es querer adquirir el deseo que no se tiene. Piénsese en esta situación. Yo no tengo el deseo de comer comida saludable todos los días, pero me gustaría tener este deseo.

3. La tercera es la de que los deseos de primer orden están en conflicto con otro deseo de primer orden. Yo quiero adelgazar y al mismo tiempo quiero comer tortillas de patatas. El deseo de segundo orden en este escenario es que yo quiero que el deseo de adelgazar prevalezca sobre el deseo de comer tortillas todos los días porque entiendo que el deseo de comer tortillas todos los días es un deseo malo debido al hecho de que yo quiero adelgazar.

Según FRANKFURT, los seres humanos son capaces de pensar sobre sus deseos y reflexionar sobre lo que les gustaría continuar deseando o no; y, eso, porque son seres que actúan conforme a razones o motivos. Por tanto, siempre que los seres humanos actúan conforme a sus deseos de segundo orden, ellos están actuando con libertad ${ }^{26}$. En este sentido, ni los adictos a una determinada droga y los agentes mentalmente perturbados, ni aquellos que tienen la compulsión de lavarse las manos hasta llegar al hueso, son libres porque no tienen la capacidad de tener deseos de segundo orden. Aunque ellos tengan el deseo de no desear usar drogas, en tanto que ese deseo no prevalezca ellos no estarán siendo libres. En síntesis, la libertad para FRANKFURT es la voluntad que es eficaz en producir comportamiento, de modo que cuando el agente manifiesta eficazmente la voluntad que desea, la voluntad como él quiere, él tiene voluntad libre, él tiene libertad, él tiene free will ${ }^{27}$.

Así, para FRANKFURT, los niños, las personas con problemas mentales o, inclusive, las personas con compulsiones (como la cleptomanía) no son autónomas y, siendo así, no son libres, porque aunque puedan tener deseos de primer orden no están en condiciones de tener metapreferencias o deseos eficaces de segundo orden. Esos agentes viven en un mundo sin capacidad autorreflexiva y, por tanto, sólo tienen deseos determinados.

24 FranKFURT, 1971: 10-11.

25 Ibid., 17-18.

26 H. FRANKFURT ha cambiado un poco este punto en trabajos posteriores. Sin embargo, no afecta a los fines de nuestra empresa. Vid. FRANKFURT, 1991: 102, 105-107.

27 Ibid., 20. 


\subsection{La condición de alternativas o de las posibilidades empíricas de elegir}

Aunque se acepte el abordaje compatibilista descrito en el punto anterior, éste, propiamente, explica sólo la acción libre bajo el aspecto de la «libertad de decisión». $Y$ esta libertad es reconocida o no a través de una lectura negativa: en caso que exista cualquier interferencia que, por sí sola, sea la causa de la decisión, el agente no será libre. Entretanto, la ausencia de constricciones no es suficiente para probar la libertad del agente; y no es suficiente porque el agente en cuestión bien puede no encontrar «condiciones para hacer lo que elige» («condición de alternativas»). Es decir, hasta aquí hemos tratado la «libertad de decisión», pero no la «libertad de acción». Por tanto, nada se ha dicho al respeto del problema de la eficacia causal de la voluntad manifestada ${ }^{28}$.

Por «libertad de acción» se puede entender la posibilidad de hacer lo que se quiere hacer. En otros términos, tener libertad de acción es poder llevar las preferencias y metapreferencias a la acción.

Dos ejemplos pueden ilustrar la diferencia entre esas condiciones de la libertad:

1. La condición de decisión está satisfecha, pero no la condición de acción: Un ejemplo evidente de la condición «de decisión» sin la condición «de acción» es la situación del coche averiado del hombre perezoso. Imaginemos que «José Perezoso» sale para comprar el pan manejando su coche y que la panadería donde compra su pan se encuentre en la misma cuadra donde él reside, de tal modo que para ir a la panadería apenas precisa salir con su coche y siempre girar a la derecha. Imaginemos ahora que el coche de «José Perezoso» tenga un grave defecto, de modo que sólo es posible que gire a la derecha. E imaginemos también que «José Perezoso» siempre giró a la derecha durante todo el tiempo en que manejó su coche, aunque tuviera la condición de decidir maniobrar a la izquierda;

2. Condición de acción sin condición de decisión: Al mismo tiempo, la situación de condición «de acción» sin condición «de decisión» puede ser imaginada cuando reflexionamos sobre la situación de aquel que, por sufrir de sonambulismo ${ }^{29}$, anda de un lado hacia el otro mientras duerme. Aun realizando movimientos, éstos no son propiamente voluntarios.

Siendo así, la «acción libre» parece depender de dos factores:

a) De que no existan impedimentos u obstáculos que imposibiliten al agente de realizar lo que quiere.

b) De que pueda decidir realizar o no realizar algo, en atención a la propia voluntad no contaminada, por factores que impidan la acción física del agente.

Se concluye, de esta forma, que la «libertad» depende de la inexistencia de «imposiciones que interfieran con la decisión» y de «imposiciones que interfieran con la acción» ${ }^{30}$. Según esta noción, pensar en un concepto de libertad sin decisión es pensar

\footnotetext{
28 O'CONNOR, 1993a: 49-52.

29 SAUL, 2008.

30 KaHANE, 1983: 245-373.
} 
en algo «sin sentido»; y pensar en un concepto de libertad sin acción es pensar en algo «vacío».

\section{EL MISTERIO DE LA LIBERTAD}

En atención a las condiciones anteriores, se plantearon objeciones incompatibilistas. Objeciones en las cuales se apoyaron algunos autores para hablar de un «misterio de la libertad», misterio que a menudo ha generado posturas escépticas con relación al problema mencionado.

\subsection{Primera objeción}

Como primera objeción específica, se ha afirmado que aunque se acepte la condición de autodeterminación como una de las condiciones para que alguien sea libre, esta condición dice poco. Y dice poco porque siempre se podrá insistir que aun las decisiones «libres» conforme a la «condición de autodeterminación» están determinadas por influjos cerebrales «en el agente» que operan conforme a las reacciones químicofísicas cuando éste delibera.

En este contexto, las tesis del «determinismo psicológico» y del «determinismo genético» resultan preocupantes. Porque considerada la tesis del determinismo psicológico, nuestro comportamiento es, de un modo u otro, psicológicamente compulsivo; y, según la tesis del determinismo genético, hacemos lo que nuestra construcción genética nos permite. Esto es, se puede decir que esa «voluntad relevante» está enteramente determinada. De esta forma, no habría real «voluntad libre». Esto significaría que no sólo hay determinación de la voluntad en las situaciones patológicas, sino también en las de «normalidad».

Además, como hemos analizado, si la propuesta de FRANKFURT es que las personas actúan libremente cuando los deseos de segundo orden se relacionan de manera específica con los deseos de primer orden, esto significa que la verdadera libertad consiste en si se pueden alterar los deseos de primer orden reflexionando sobre esos deseos. El problema de esta formulación — dicen los incompatibilistas — es que se puede también preguntar por qué en su «metapreferencia» el agente es libre.

Considerando esta insistencia, un camino probable pasa a ser el de reconocer que pensar sobre la libertad es una pérdida de tiempo, al menos, una empresa que, por estar destinada al fracaso, no presenta muchas ventajas (cuando nos ocupamos de ella).

Th. NAGEL, por ejemplo, asume esta posición. Para NAGEL,

[...] existen diversas posibles soluciones [para el problema de la determinación de la libertad] y no sabemos cuál es la correcta. Este es un caso en el cual, en el transcurso de una amplia discusión pública sobre el tema, nadie propuso ninguna cosa increíble ${ }^{31}$.

Además, NAGEL no está solo en este punto. Es conocida la defensa de P. VAN INWAGEN según la cual la libertad es un «misterio sin solución» ${ }^{32}$. De ahí, pasa a afirmar que

\footnotetext{
31 Nagel, 1996: 163.

32 VAN INWAGEN, 1983: 174.
} 
[...] por considerar imposible encontrar una solución a este problema, es interesante la sugerencia recientemente formulada por N. Chomsky [...]. Según Chomsky, en nuestra biología, en la forma con la cual el pensamiento fue «instalado» en nuestros cerebros, existe alguna cosa que hace que para nosotros, los seres humanos, sea imposible resolver el misterio de la libertad ${ }^{33}$.

Para apoyar sus conclusiones VAN INWAGEN no esconde referencias a las ideas de C. MACGINN, autor que, como CHOMSKY, señaló que «el libre albedrío es un misterio y en eso consiste su posibilidad» ${ }^{34}$. Es decir, lo que está detrás de estas posturas encuentra su razón de ser en la consideración del plan interno o mental de las decisiones.

En ese paso, la formulación de MACGINN es relativamente sencilla. Para MACGINN, cuando un agente quiere comer alguna cosa y ve una manzana sobre la mesa, la coge para comérsela. Este es un ejemplo típico de causalidad mental. Sin embargo, en esta decisión, mejor dicho, en la trayectoria de esta causalidad mental, ¿existe algún espacio para la libertad? Según MACGINN, no. De esta manera, tanto los incompatibilistas «liberales» como los «compatibilistas» no habrían resuelto la cuestión satisfactoriamente: todas esas construcciones fallan teniendo en cuenta que la causalidad mental — que es según MACGinN el real lugar de discusión de la libertad— es irreductible a la causalidad física y, por tanto, no puede ser tratada como una «causa externa de constricción». Siendo así, siempre según MACGINN, un modelo explicativo de la causalidad mental que quiera ser suficiente al explicar las acciones no compulsivas debe abordar el problema del control que el agente tiene sobre sus propias acciones y de la posibilidad de decidir diversamente frente a las opciones que le son presentadas ${ }^{35}$.

\subsection{Segunda objeción}

Como segunda objeción específica se puede decir que la condición de las posibilidades alternativas de elección es cuestionable. En este punto se puede traer a colación el ejemplo de la «habitación cerrada» de LOCKE.

LOCKE, en el $\$ 10$ del capítulo XXI titulado «Del poder», en sus Ensayos sobre el entendimiento bumano, pregunta si podemos dudar de la libertad de un agente que, en un sueño profundo, es conducido hasta una habitación donde se encuentra una persona que él deseaba mucho ver ${ }^{36}$. LOCKE cuestiona si podemos considerar libre al agente si suponemos que éste al despertarse y al ver a dicha persona se pusiera tan feliz que resolviese quedarse conversando con ella. La respuesta de LOCKE es que el agente continúa siendo libre, aunque la puerta cerrada sea un obstáculo real a la opción alternativa. Según LoCKE, dado que la decisión del agente habría sido la de quedarse, poco importa si él desconoce o no que ésta era su única opción: porque apenas hay un límite para la libertad si se anula el ejercicio del poder de actuar, lo que no ocurre en este caso.

Ya sabemos que el determinismo causal supone cierta comprensión de «cómo» algunas cosas ocurren en el mundo físico, es decir, partimos de la comprensión según

33 CHOMSKY, 1975: 174-175.

34 MaCGINN, 1999: 168.

35 Ibid., 167-168.

36 LOCKE, 2000: cap. XXI. 
la cual el mundo físico está causalmente regulado por acontecimientos precedentes y sucesivos, condicionados por los acontecimientos precedentes. Siendo así, el cuerpo humano está sometido a este dato elemental: cuando muevo la pierna hacia delante este movimiento está determinado por causas físicas que posibilitan el movimiento entre las cuales, algunas de las cuales las puedo inclusive desconocer. Pero si esto es correcto en todas las situaciones, algo suena raro. Por ejemplo, cuando tengo hambre, mi impulso es el de alimentarme. Entretanto, puedo negar este impulso y quedarme con hambre, de manera que al pasar por una tienda de frutas no cojo el alimento y simplemente resuelvo la cuestión de mi hambre, porque sé que esto sería hurtar. Así, es cierto que hay algo de físico y determinado (el movimiento de mis piernas y de mis brazos al andar), pero también existe algo que, al menos, creemos que escapa a las leyes del mundo físico, es decir (manteniendo el ejemplo), el hecho de negarme a hurtar. Mejor dicho, es exactamente esta percepción que compone tan expresivamente el simbolismo de la «huelga de hambre»: decido a cada momento que no comeré, a pesar de que esto le esté haciendo mal a mi cuerpo y, en último análisis, que esta actitud pueda matarme.

Se tiene, por consiguiente, la percepción según la cual si lo mental fuese reducido sólo a lo físico, yo estaría completamente determinado por la causalidad física y, por consiguiente, no podría actuar sino conforme a las relaciones causales físicas implicadas. Y esas consideraciones parecen incomodar en la medida en que se advierte la presencia de partes de nuestro cuerpo físico las cuales parecen depender de una decisión nuestra (como mis pasos) y otras que son independientes de ella (el funcionamiento de mis riñones). Pero si parto de la noción de que la mente y el cuerpo son distintos, como parece ser inevitable para hacer el enunciado «Soy libre para hacer lo que quiero» verdadero o plausible, preciso admitir que lo mental está regido por leyes propias, y esto significa que no todo mi cuerpo está causalmente determinado. El problema es que, siendo así, estoy asumiendo dos explicaciones como correctas, aunque sean excluyentes en la explicación de un mismo fenómeno: mi acción (la acción humana en general) se encuentra regida por dos series causales, una física y otra mental, como si hubiese una «mente desencarnada». Y en esto se resume el «misterio de la libertad»: la opción mental no es una solución si yo estuviera condicionado a ella como lo estoy en mi vida física. Pero si mi vida mental no estuviese regida por la causalidad, ¿qué la regiría?

\section{APENAS UNA ILUSIÓN}

Ante todos los obstáculos evidenciados, cabe preguntarse cuál es la solución para el problema de la libertad. Porque, si por un lado comprender la libertad en su relación última con los impulsos mentales parece llevarnos a un callejón sin salida, por otro lado admitir que no somos libres parece resultar en la aceptación de la irresponsabilidad individual y de la ineficiencia de las normas como instrumentos de control social ${ }^{37}$.

37 Esta percepción, de cualquier modo, según entendemos, es falsa. Aunque este no sea el objeto de este estudio (dado que este aspecto se relaciona más con el proyecto «normativo» mencionado en la introducción que con el «substancial»), se puede resolver este punto asumiendo una posición justificativa consecuencialista del castigo en lugar de la retribucionista. Como se sabe, el «retribucionismo» se basa en la idea de que el agente debe ser sancionado porque «merece serlo» y en la medida en que lo merezca; el «consecuencialismo» 
Frente a esta situación, algunos autores han utilizado el vocablo «ilusión» y han dicho que hay una «función social de la ilusión de la libertad» o de la «aceptación de que somos libres sin más amplias indagaciones».

Así, para S. SMILANSKY, por «ilusiones» se debe entender el posicionamiento frecuentemente asumido como lo necesario para que nosotros seamos libres. La «ayuda de esta ilusión» se sitúa en la propia función que desempeña; y por ser muy importante en términos de organización social, la misma debe ser mantenida ${ }^{38}$. Porque creer en la ilusión de las decisiones libres, en términos básicos, posibilita que las personas asuman sus actos sintiéndolos como propios y con eso puedan sentir remordimientos ${ }^{39}$.

La humanidad, dice SMILANSKY, afortunadamente se decidió por esta ilusión y fue por esta decisión que la civilización pudo avanzar con la moral y los valores personales de cada uno. Por ello, afirma que la ilusión de la libertad está compuesta, por un lado, por la conclusión falsa de la libertad; y, por otro lado, por la necesidad de mantener esta percepción falsa de las $\operatorname{cosas}^{40}$.

La ilusión a la que se refiere SMILANSKY atiende a una necesidad práctica: la necesidad de reprimir, de aprender y de que, con esto, podamos ser felices gobernados por parámetros que nosotros mismos establecemos socialmente. Pero esto no significa que esta ilusión iguale la voluntad contaminada con la no contaminada. Forma parte de esta ilusión la idea de que en las situaciones en que el agente actúa sufriendo alguna contaminación en su voluntad, ésta debe encontrar menos reprimenda que si tal contaminación no existiera. En ese sentido, en la mayoría de los casos, esta ilusión es positiva, teniendo en cuenta que la «ilusión de la libertad» posibilita alguna percepción colectiva $^{41}$.

En resumen, SMILANSKY encuentra la respuesta de la necesidad a los problemas del debate entre los incompatibilistas y los compatibilistas. Para SMILANSKY, hay buenas razones psicológicas y filosóficas para la ilusión: la ilusión es la condición humana.

\section{MI CEREBRO ME HIZO HACER ESO}

Unas de las afirmaciones sólidas en la literatura sobre el cerebro es que nosotros somos nuestro cerebro o, al menos, cuando nuestro cerebro sufre alguna alteración hay registros de «alteración en nuestro yo» ${ }^{42}$. Esto no ocurre, por ejemplo, cuando

se basa en la idea, más utilitarista, según la cual el agente debe ser castigado para «beneficio del grupo o la sociedad» de modo que los agentes potencialmente peligrosos podrían ser «detenidos para evitar más crímenes». Siendo así, aunque bajo el primer punto de vista un agente completamente determinado no «merecería la pena» nada impide que asumiendo el segundo modelo sea sancionado para «beneficio del grupo». El aspecto clave es la percepción de la libertad que está en juego (agradezco al grupo de investigadores de la Universidad de Alicante por solicitar esta aclaración, la cual dio origen a este párrafo). Para este punto, vid. NINO, 1987: 106-108.

38 SMILANSKY, 2000a: 169-170.

39 SMILANSKY, 2000b: 88-94.

40 SMilansky, 2000a: 170-171.

${ }^{41}$ Ibid., 204-205.

42 Uno de los casos frecuentemente referidos para demostrar esta relación ha sido ampliamente divulgado en el año 2002. Un hombre de 40 años de edad, profesor de escuela, comienza a visitar sitios web de pornografía infantil. Amigos y familiares se extrañaron su comportamiento y después de un examen y una investigación 
sufrimos alguna lesión en nuestro brazo o pierna o, inclusive, en la espalda. Pero cuando partes de nuestra cabeza quedan afectadas perdemos la capacidad de hablar, de expresar emociones, de ver, en fin, de realizar actividades comunes.

\subsection{State of Utah vs. Tomas R. Herrera}

Pocos minutos después de la medianoche del día 6 de junio de 1991, Tomas R. Herrera entró en la casa de su ex-novia Claudia Martínez ${ }^{43}$, se dirigió a su habitación y, después de estrangularla, le disparó en la cabeza dos veces, provocándole la muerte. Al salir de la habitación, Herrera se encontró con la madre de Claudia, Rosa, en la sala. Rosa, notando lo ocurrido, intentó escapar yendo a la habitación de su hijo Reuben. Herrera la persiguió y, una vez dentro de la habitación de Reuben, le disparó causándole lesiones no fatales. Se dirigió también a Reuben y le disparó errando el blanco. Lo intentó algunas veces más, pero se quedo sin munición.

Avisada por los vecinos, llegó la policía y detuvo a Herrera, leyéndole sus derechos. Herrera le contó a la policía que estaba conduciendo su coche cerca de la residencia de Claudia cuando perdió el control sobre sí mismo y decidió matarla; admitió haberlo hecho y haber atentado contra la vida de Rosa y Reuben. El Estado de Utah ejerció una acción penal contra Herrera acusándolo de homicidio y de doble atentado a la vida.

El Dr. Breck Lebegue, especialista forense, fue llamado para examinar el estado mental de Herrera en el momento de los disparos. Basándose en el examen realizado, el Dr. Breck Lebegue concluyó que Herrera sufría del Síndrome de Capgrass ${ }^{44}$. Conforme a su opinión, cuando Herrera mató a Claudia «él creía que estaba matando a alguien que no era un ser humano» ${ }^{45}$. Según Herrera la mafia capturó a su ex-novia y colocó en su lugar a una impostora.

También conforme a la opinión del Dr. Breck cuando Herrera atentó contra la vida de Rosa y Reuben, él sabía que estaba atentando contra la vida de seres humanos.

Herrera fue condenado por el atentado a la vida de Rosa y Reuben y considerado mentalmente enfermo en cuanto a la acusación de matar a Claudia.

al respecto sobre los fuertes dolores de cabeza que sentía fue detectado por el fMRI un tumor casi del tamaño de un pequeño huevo en su lóbulo frontal. Después de una operación que retiró el tumor, sus impulsos de visitar los sitios web de pornografía infantil cesaron. Meses después vuelve a sentir impulsos pedofílicos y fuertes dolores de cabeza. Los exámenes realizados identifican que un nuevo tumor había crecido en el lugar del antiguo. Esta fue la primera vez que relacionaron los problemas en el cerebro con el comportamiento pedofílico. Burns; Swerdlow, 2003; Tost; Vollmert; Brassen; SchmitT; Dressing; Braus, 2004; SChiffer; Peschel; Paul; GiZewski; Forsting; Leygraf; SCHEDlOWski; KRUEgER, 2007.

${ }_{43}$ Supreme Court of State of Utah, Plaintiff and Appellee vs. Tomas R. Herrera, Defendant and Appellant, No. 980145, FILED June 29, 1999.

${ }^{44}$ El Síndrome de Capgrass fue descrito por primera vez por Joseph Capgrass, psiquiatra francés, en 1923 al estudiar una paciente que continuamente sostenía que «dobles» habían tomado el lugar de su marido y otros conocidos. Una característica de este síndrome es el no reconocimiento de personas, lugares u objetos como «reales», pudiéndose manifestar de forma leve o muy grave. En casos graves las personas son consideradas como «impostoras», «alienígenas» o «robots». Este síndrome se relaciona con sucesos de lesiones cerebrales comunes en accidentes que afectan a la cabeza. ELLIS; LEWIS, 2001.

${ }^{45}$ Supreme Court of State of Utah, Plaintiff and Appellee vs. Tomas R. Herrera, Defendant and Appellant., No. 980145, FILED June 29, 1999. 
La defensa de Herrera argumentó para el recurso que teniendo en cuenta que se ha considerado enfermo a Herrera y, por tanto, no pasible de encarcelamiento por la muerte de Claudia, se debería utilizar el mismo argumento para los atentados contra la vida de Rosa y Reuben, considerando que forman parte del mismo episodio de crisis. Este argumento fue rechazado por el juez dado que, según la opinión del especialista, distinguir víctimas no es incompatible con el síndrome, de modo que puede sufrir locura en cuanto a determinadas personas y no en cuanto a otras.

\subsection{People State New York vs. Herbert Weinstein}

«Yo no hice eso, fue mi cerebro» es la síntesis de una defensa paradójica según la cual los defectos en el cerebro - demostrados por fMRI (Resonancias Magnéticas Funcionales) - sugieren el origen del acto violento ${ }^{46}$.

En lo referente al caso People State New York vs. Herbert Weinstein ${ }^{47}$, de 1992, el abogado de 65 años de edad Herbert Weinstein fue acusado de asesinato. Conforme a la acusación, Weinstein mató a su mujer, Bárbara, por estrangulamiento, y para encubrir el crimen, fingió un suicidio arrojándola desde el $12 .^{\circ}$ piso del apartamento en el que vivían en Manhattan.

Con el objetivo de apoyar la defensa, se anexaron los escáneres del cerebro de Weinstein (PET - Positron Emission Tomography). El propósito de las imágenes era el de posibilitar que neurólogos y psiquiatras estudiasen las funciones metabólicas del cerebro de Weinstein en sus varias regiones. La defensa de Weinstein afirmó que él tenía lesiones en el lóbulo frontal del cerebro causado por un quiste aracnoideo, de modo que, según los especialistas, su presencia se encontraría exactamente en la parte del cerebro que controla todo el pensamiento y el comportamiento voluntario ${ }^{48}$.

La acusación arguyó que la prueba del quiste aracnoideo no debería ser admitida en el proceso. Conforme a la decisión del juez Richard Carruthers, bajo la regla de la admisibilidad de la prueba, podían mostrarse las imágenes del cerebro, pero no sería posible decirles a los jurados que éstas estarían indiscutiblemente relacionadas con

46 Se registra el caso de Brian Dugan como el primero en utilizar esa técnica para efectos judiciales (antes de eso otra técnica ya había sido empleada para analizar la condición cerebral de John Hinckley Jr., cuando éste atentó contra la vida del presidente de los Estados Unidos, Ronald Reagan, para llamar la atención de la actriz Jodie Foster). Dugan fue sometido a un exhaustivo examen de resonancia magnética cerebral (fMRI) por más de 90 minutos, bajo la supervisión de Kent Kiehl, neurocientífico de la Universidad de Nuevo México. El propósito del examen era comprender cómo funcionaba el cerebro de Dugan y si era posible usar esos datos en el juicio. Dugan había sido condenado por estupro y asesinato de 3 personas. Jeanine Nicarico, de Illinois, fue su primera víctima. En el año 1983 Dugan la llevó a su coche y la violó en el asiento de atrás golpeándola hasta matarla. En el año 1984 mató a su segunda víctima, una enfermera. El crimen fue parecido al primero. Dugan la violó y la mató abandonando su cuerpo inerte poco después. El tercer crimen tuvo como víctima una niña de 7 años de edad que estaba andando en bicicleta. Dugan la violó y la mató, tirándola a la basura. HuGHES, 2010: 340-342.

47 Supreme Court of New York, People State New York, vs. Herbert Weinstein, October 8 (1992).

48 El lóbulo frontal en los seres humanos es responsable del control de las llamadas funciones ejecutivas del cerebro. La habilidad de actuar racionalmente y de planear constituyen sus más importantes funciones. El lóbulo frontal, en otras palabras, es el área responsable del poder cognitivo humano. Según las evidencias disponibles, los daños al lóbulo frontal pueden generar efectos adversos en la capacidad de la persona de actuar racionalmente. 
la violencia. Fundamentó su decisión invocando precedentes de People vs. Stone ${ }^{49}$ y People vs. Sugden ${ }^{50}$. El especialista forense, Dr. Daniel Martell, por tanto, sólo declaró que la tecnología era nueva y prometedora en el análisis del comportamiento humano.

Conforme a lo expuesto por el especialista Daniel Martell, «las debilidades cognitivas son señales de disfunción en el lóbulo frontal». Según él, «los daños en el lóbulo frontal pueden presentar erosiones en la capacidad de juicio de la persona. Este es el aspecto generalmente aceptado como válido en el campo de la psiquiatría, psicología y neurología» ${ }^{51}$. Esas lesiones fueron provocadas por un quiste aracnoideo. Los quistes aracnoideos son sacos de líquido localizados entre las membranas que cubren el cerebro que forman una red parecida a una tela de araña, como el propio nombre sugiere. Los quistes aracnoideos son de naturaleza congénita, es decir, ya están presentes en el nacimiento.

Once días después del cierre de las consideraciones, el acusado fue condenado con una reducción de pena. A partir de este caso, la pericia de neurocientíficos es frecuente en otros procesos, sobre todo norteamericanos.

\subsection{Roper vs. Simmons}

Los niños pueden saber lo que es correcto y lo que no. Hay estudios que señalan que los niños de hasta seis años de edad saben que matar es incorrecto. Entretanto, dada la inmadurez de sus cerebros, los niños y los adolescentes tienen menor capacidad para controlar sus impulsos, para usar la razón como guía de comportamiento o, inclusive, para reflexionar con respecto a las posibles implicaciones de sus actos. Esta fue la conclusión del caso Roper vs. Simmons, según la cual condenar niños y adolescentes a muerte viola la Constitución norteamericana ${ }^{52}$.

Con apenas diecisiete años de edad, Christopher Simmons planeó el asesinato de Shirley Crook conjuntamente con dos amigos: Charles Benjamin y John Tessmer. El plan era cometer un asalto y matar a la víctima arrojándola desde un puente. En el medio de la noche los tres se encontraron, pero John Tessmer desistió en el último instante. Simmons y Benjamin entraron en la casa de la víctima; robaron y cubriéndole la cabeza a Shirley y atándole las manos la arrojaron desde el puente.

En el juicio las pruebas en contra de Simmons fueron consideradas consistentes, inclusive contando con su confesión, habiéndose realizado una reconstrucción del crimen con la presencia del propio Simons y grabado en video para ser mostrada al Jurado. Después de deliberar, el Jurado retornó con el veredicto de pena de muerte, incluso habiendo tenido en cuenta las circunstancias atenuantes del caso. Simmons a partir de entonces aguardaría la fecha para su ejecución.

Sin embargo, en el año 2002, la Suprema Corte decidió el caso Atkins vs. Virginia, según el cual las personas con problemas mentales no podrían ser condenadas a la pena

4935 N.Y. 2d 69 (1974).

5035 N.Y. 2d 453 (1974).

5135 N.Y. 2d 453 (1974).

52 Ropervs. Simmons, 543 U.S. 551 (2005). 
de muerte. La defensa de Simmons, así, presentó una solicitud para que se considere el caso de adolescentes con el fin de extender la imposibilidad de la pena de muerte ${ }^{53}$.

El 13 de octubre de 2004 la Suprema Corte retomó el caso Simmons y, aceptando la posición de especialistas, estableció, en su decisión, tres razones para impedir que jóvenes criminales sean incluidos entre los criminales pasibles de pena de muerte.

En primer lugar,

[la] falta de madurez y un sentido de responsabilidad subdesarrollado se encuentra con más frecuencia en jóvenes que en adultos; y son más comprensibles entre los jóvenes. Estas cualidades muchas veces tienen como resultado acciones y decisiones impetuosas o irreflexivas ${ }^{54}$.

La segunda área de diferencia es que los jóvenes son más vulnerables o susceptibles a influencias negativas y presiones externas, incluyendo la presión de los colegas ${ }^{55}$.

La [j] uventud es más que un hecho cronológico. Es un tiempo y una condición de vida, cuando una persona puede ser más susceptible a la influencia y a los daños psicológicos. Esto se explica en parte por la circunstancia predominante de que los jóvenes tienen menos control, o menos experiencia con el control, sobre su propio ambiente ${ }^{56}$.

La tercera gran diferencia es que el carácter de un joven no está tan bien formado como el de un adulto. Los trazos de personalidad de los jóvenes son más transitorios, menos fijos. Esas diferencias hacen dudar de las conclusiones de que un joven se encaje entre los peores criminales; «...su conducta irresponsable no es tan moralmente reprobable como la de un adulto», decidió la Corte. Su propia vulnerabilidad y comparable falta de control sobre su entorno inmediato significa que «...los jóvenes merecen más perdón que los adultos por no escapar de las influencias negativas de su medio ambiente» ${ }^{57}$.

En este sentido, en Simmons la Corte decidió que: a) las personas menores de 18 años son diferentes y esta diferencia resulta de un proceso cerebral en formación; b) puede haber excepciones a la afirmación presente en $a$ ), pero nadie puede decir con certeza qué excepciones son esas, y c) respecto a la pena de muerte, la Corte establece un límite a su imposición a menores de dieciocho años de edad.

\subsection{Schwarzenegger vs. Entertainment Merchants Ass'n}

Recientemente, en el caso Schwarzenegger vs. Entertainment Merchants Ass'n, la Suprema Corte Norteamericana anuló una ley del Estado de California que prohibía la venta o alquiler a menores de videojuegos que hayan sido «catalogados como juegos violentos» (California Civil Code, Section 1746.1) ${ }^{58}$. La justificación de la ley califor-

53 US Supreme Court, núm. 03-633, Donald P. Roper vs. Christopher Simmons, Brief for the American Psychological Association, and the Missouri Psychological Association as Amici Curiae: 1-30.

54 Johnson, at 367, 125 L. Ed. 2d 290, 113 S. Ct. 2658; vid. también Eddings, at 115-116, 71 L. Ed. 2d 1, 102 S. Ct. 869.

55 Eddings, at 115, 71 L. Ed. 2d 1, 102 S. Ct. 869.

56 Vid. Steinberg \& Scott, 58 Am. Psychologist 1009, 1014 (2003).

57 Stanford, 492 U.S., at 395, 106 L. Ed. 2d 306, 109 S. Ct. 2969 (Brennan, J., dissenting).

58 Schwarzenegger vs. Entertainment Merchants Association, 08-1448. 
niana es la afirmación según la cual los videojuegos violentos pueden causar problemas psicológicos serios en menores de dieciocho años de edad.

El caso se inició el 7 de octubre de 2005, cuando el entonces gobernador del Estado de California, Arnold Schwarzenegger, firmó la ley California Civil Code \$\$ 17461746.5 que prohíbe el alquiler o la venta de juegos violentos a menores estableciendo una sanción de 1.000 dólares por su violación. Según la definición de la referida ley, un juego es violento cuando:

[...] la gama de opciones disponibles para un jugador incluye asesinato, mutilación, desmembramiento o abuso sexual de la imagen de un ser humano, si esos actos están representados en el juego de una manera que realiza cualquiera de las siguientes condiciones:

i) Una persona razonable, teniendo en cuenta el juego en su conjunto, encontraría apelaciones [sic] a un interés desviado o morboso de los menores.

ii) Es claramente ofensivo a las normas vigentes en la comunidad en cuanto a lo apropiado para menores.

iii) Hace que el juego, en su conjunto, carezca en forma grave de valor literario, artístico, político o científico para los menores.

iv) Permite al jugador infligir virtualmente graves lesiones a las imágenes de seres humanos o personajes con características sustancialmente humanas de una manera que es especialmente atroz, cruel o depravada en cuanto implica abuso físico o tortura grave a la víctima.

Antes que la ley produjera sus efectos, Entertainment Merchants Association y Entertainment Software Association, alegando violación del derecho a la libertad de expresión protegido en la Primera Enmienda de la Constitución Americana, invocaron su inconstitucionalidad ${ }^{59}$. El Estado de California presentó en sus alegaciones la opinión de especialistas y varias escenas violentas de videojuegos, tales como «Grand Theft Auto Vice City» $\mathrm{y}$ «Duke Nukem 3D» en los cuales las personas son asesinadas de formas distintas y brutales. El tribunal distrital decidió a favor de los productores y distribuidores de juegos. Después de apelar a la 9. ${ }^{a}$ Corte distrital ésta confirmó la decisión local.

El Estado de California pidió entonces que la Suprema Corte debería declarar la constitucionalidad de la ley californiana bajo el estándar legal establecido en Ginsberg vs. New York, referido a la prohibición de la exposición de material de contenido sexual. Para reforzar su posición anexó estudios analizando el impacto de materiales violentos, incluyendo en ellos videojuegos. Considerando el vasto interés del mercado en el caso, 31 opiniones de especialistas fueron presentadas al mismo, financiadas tanto por defensores de la ley como por aquellos que deseaban la declaración de su inconstitucionalidad y, por tanto, la libertad de venta de los videojuegos.

Apoyando la posición del Estado de California, tanto la Asociación Americana de Psicología (APA, por sus siglas en inglés, 2005) como la Academia Americana de Pediatría (AAP, por sus siglas en inglés, 2009) emitieron declaraciones formales afirmando que investigaciones científicas

concluyen que la exposición a videojuegos violentos provoca un aumento en la probabilidad en el comportamiento posterior agresivo en niños y adolescentes [...] y también que

59 Amendment I. «Congress shall make no law respecting an establishment of religion, or probibiting the free exercise thereof; or abridging the freedom of speech, or of the press; or the right of the people peaceably to assemble, and to petition the government for a redress of grievances». 
se ha apreciado que los videojuegos violentos aumentan los pensamientos agresivos, los sentimientos de agresividad, la desensibilización a la violencia física y disminuye el comportamiento prosocial ${ }^{60}$.

Conforme a la decisión de la Suprema Corte,

dado que el acto implica una restricción en el contenido del discurso protegido, esto es inválido a menos que California pueda demostrar que está justificado por un interés gubernamental convincente y está estrechamente demarcado para servir a dicho interés [...].

Según la conclusión de la Corte, «El Estado de California no logró presentar este estándar» ${ }^{61}$.

\section{LA HIPÓTESIS DE LA LIBERTAD}

A partir de este punto presentaré tres ajustes sobre la manera de pensar el tema de la libertad expuesto hasta ahora. Designaré a estos ajustes, respectivamente: ajuste «descriptivo»; ajuste «sustancial» y, finalmente, ajuste «normativo». Con el ajuste de «descriptivo» se intenta resolver el problema del salto lógico; con el ajuste de «sustancial» la cuestión de la reducción descriptiva y su relación con la hipótesis de la libertad; con el ajuste «normativo» presentaré el ámbito del posible aprovechamiento de los esfuerzos del neuroderecho.

\subsection{Primer ajuste: ajuste descriptivo}

Como observa VON WRIGHT, es un error equiparar el determinismo de las ciencias de la naturaleza y el determinismo de las ciencias sociales. Mientras el primero se funda en la universalidad de las experiencias físicas, el último se encuentra vinculado a convenciones y presiones sociales ${ }^{62}$. Por eso el objetivo de ambos es diferente: mientras las ciencias de la naturaleza estudian los fenómenos del reino de las leyes naturales, las ciencias humanas estudian el reino social de las instituciones y de sus reglas ${ }^{63}$.

Esto no significa, conforme a lo que señala VON WRIGHT, que no existan analogías entre las ciencias naturales y las humanas, pues tanto las leyes sociales como las leyes naturales «gobiernan» en sus ámbitos: la «sociedad» y la «naturaleza», aunque en un sentido prescriptivo para las primeras y apenas descriptivo para las segundas ${ }^{64}$. Sin embargo, las diferencias son relevantes:

En las ciencias naturales las ideas deterministas se encuentran relacionadas con otras ideas, las cuales asumen la regularidad universal, la repetición, y el control experimental.

En las ciencias humanas, las conexiones inmediatas están limitadas a la motivación y a la

${ }^{60}$ Brief of Amicus Curiae of California State Senator Leland Y. Yee, Ph. D., the California Chapter of the American Academy of Pediatrics, and the California Psychological Association in Support of Petitioners, Brown vs. Entm't Merchs. Ass'n, 130 S. Ct. 2398 (2010) (No. 08-1448), 2010 WL 2937557.

${ }^{61}$ Supreme Court, Schwarzenegger vs. Entertainment Merchants Association, Argued November 2, 2010, Decided June 27, 2011.

62 VON WRIGHT, 1976: 415.

63 Ibid., 415.

${ }^{64}$ Ibid., 415-416. 
presión social, a las directivas y a la intencionalidad. En las ciencias naturales el determinismo sirve ampliamente para establecer predicciones; en las ciencias humanas la mirada más fuerte enfatiza explicaciones retrospectivas ${ }^{65}$.

En esos términos, las ideas deterministas, teniendo en cuenta las diferencias señaladas, no son las mismas. Y esas diferencias de ninguna manera pueden ser ignoradas, a pesar de que muchos insistan en la mistificación de la naturaleza intentando englobar al hombre en consideraciones que no le caben. Y es esta equivocación que, según vON WRIGHT, ha limitado el análisis del hombre a las causas internas cuando la libertad debe ser analizada también sobre el aspecto social, mejor dicho, en su voluntad, en sus deseos, en sus pasiones, en sus sentimientos y en sus deliberaciones manifestadas. Así, la libertad humana está mejor circunscrita cuando se analiza sobre el aspecto contextual de las relaciones humanas institucionales, y no como «relaciones químicoeléctricas».

A partir de VON WRIGHT, lo que se ha observado puede, ahora, ser explicado, con SCHLiCK, con la expresión «error de categoría». Porque SCHLicK, al referirse a las leyes sociales y a las leyes humanas, aclara que esas no pertenecen a la misma categoría de sentido, y lo hace, en primer lugar, con notas de precisión sobre los sentidos de $« l e y »{ }^{66}$.

Resalta SCHLICK que, en la práctica, por «ley» se han designado ciertas prescripciones dirigidas al comportamiento de los individuos. Una de las maneras más eficientes de hacerlos obedecer es estableciendo sanciones (penalidades) que en razón de sus consecuencias obligan a los agentes a actuar de determinada manera. Sin embargo, en las ciencias de la naturaleza «ley» significa algo distinto; «ley» no es una prescripción que establece cómo debemos actuar, sino una fórmula, una descripción de cómo funciona la naturaleza ${ }^{67}$. Queda claro que ambas «leyes» (natural y social) presentan algo en común: ambas expresan una «fórmula», es decir, de cómo debemos proceder (leyes sociales) y de cómo opera la naturaleza (leyes de la naturaleza). Exceptuando esto, dice SCHLICK, nada más las aproxima. La ley de la mecánica del universo no prescribe a los planetas cómo deben moverse: esto significa que la teoría de KEPLER en nada interfiere en el movimiento de los planetas. De esto resulta la confusión relacionada con los eventos y con la necesidad natural. Se dice que los eventos humanos y los eventos físicos obligan a los individuos cuando ninguna voluntad existe en la naturaleza ${ }^{68}$.

Siendo así, afirma SCHLICK, «libertad» es el contrario de «imposición»; un hombre «libre» es un hombre que no está sometido a «imposiciones» que le impidan para poder realizar sus deseos, como el enfermo mental y en ciertos casos, las drogas. Sin embargo, la naturaleza no prescribe, ella no impone nada. Por eso la validez universal de la leyes de las ciencias naturales no puede ser confundida con la aplicación de las leyes del Estado, ni siquiera la propia naturaleza excluye la libertad ${ }^{69}$.

Teniendo en cuenta esos datos la correcta comprensión de la libertad supone ubicarla en un espacio de «ausencia de constricción» y, por tanto, comprender el sig-

\footnotetext{
65 Ibid., 416.

66 SCHLICK, 1939: 146.

67 Se trata, por tanto, sólo de una generalización nómica. KISTLER, 1999: cap. 2.

68 SCHLICK, 1939: 149.

69 Ibid., 146-147.
} 
nificado de la expresión «ser compelido a» ${ }^{70}$. Porque «ser compelido» implica una relación de poder y la naturaleza no ejerce ninguna relación intencional; ella no ejerce un «poder» sobre los hombres, a menos que se asuma el vocablo «poder» de modo desencajado de sus implicaciones sociales intersubjetivas.

\subsection{Segundo ajuste: ajuste sustancial}

El segundo ajuste se basa en el estudio de J. L. Austin llevado a cabo en el ensayo «A Plea for Excuses», publicado en los Proceedings of the Aristotelian Society, años de 1956-1957. El trabajo de AusTiN se centra en el concepto de «disculpa» y en el «acto de disculparse» ${ }^{71}$ y como tal es decisivo para la comprensión de lo que puede llamarse aquí función social de la noción de libertad.

Según Austin, cuando nos disculpamos por algo, expresamos que nuestra acción no salió bien o como nos hubiese gustado que saliera de otra manera. Por tanto, el vocablo «disculpa» es una etiqueta bastante general que abarca toda una familia de nociones, tales como: la «justificación», los «atenuantes», las «excusas», los «pretextos», las «agravantes», los «paliativos», etc. A todos estos sustantivos pueden ser añadidos los términos que sirven para calificar las acciones; conjuntamente considerados, ellos sirven para caracterizar las acciones humanas. Y algunos de los términos que califican las acciones son más comunes que los otros, como «libremente», «torpemente», «espontáneamente», «obligatoriamente», «deliberadamente», etc. Entiende AusTiN que, de esta manera, el estudio de las disculpas es parte relevante del examen de las acciones y este es el camino para el estudio de la libertad humana ${ }^{72}$.

AUSTIN llama la atención sobre la diferencia existente entre el acto de «disculparse» y el de «justificarse» con alguien. Ambas son formas de defensa en relación con una acción defectuosa.

Supongamos que un agente $X$ hizo algo y se «disculpa» por haberlo hecho. $P$, su abogado, admite que $X$ realizó el acto por el cual está siendo imputado, pero niega que haya habido un crimen. Esto es «justificar» la acción de $X$. Sin embargo, existe otra línea aún más frágil. Se puede decir que aunque $X$ haya realizado lo que se le imputa y por eso mismo que su acto es reprochable, no lo realizó de modo «puro»: la furia que lo embargaba hizo que $X$ no estuviera condiciones de controlarse. Estamos aquí ante una «disculpa». La cuestión es que si $X$ actuó libremente y hay una acción que le es imputada como socialmente negativa (un crimen), entonces merece un castigo, aunque menos acentuado, considerando las peculiaridades del caso $^{73}$.

Los ejemplos anteriores de Austin, mutatis mutandis, son aplicables al problema de la libertad. Porque un agente es responsable (al menos moralmente) por sus acciones cuando éstas son realizadas libremente. Entonces, ¿cuándo puede utilizarse el adverbio «libremente»? Esta cuestión hace más claro algo que había escapado a la percepción del problema de la libertad explorada en los apartados anteriores: la libertad

\footnotetext{
70 O'CONNOR, 1993b: 499-500.

71 Austin, 1955: 1-3.

72 Ibid., 3.

73 Ibid., 3-4.
} 
no es una cuestión de todo o nada Por tanto, en la búsqueda de las condiciones de la libertad debe incluirse la percepción de que el abordaje entre determinismo y libertad es, en gran medida, equivocado, pues la comprensión de la libertad está circunscrita a la caracterización de ciertas acciones, no a todas las acciones: apenas se puede ser libre en lo que es posible actuar libremente. El abuso en el empleo de adverbios como «libremente» sin este mínimo cuidado produce falsos problemas.

En el fondo, lo que está aquí en juego es la noción de «libertad en sentido ontológico», por un lado, y, por otro, la noción de «libertad social» y sus posibles relaciones ${ }^{74}$. Mientras la investigación de la libertad ontológica la coloca en el marco de la atemporalidad e intenta entender sus posibilidades en abstracto, la libertad social (que puede ser «política», «moral», «religiosa», «jurídica», «económica», etc.) es pragmática y considera datos específicos como ya operantes, puesto que las formas de constricción social son múltiples. Esto es, mientras las cuestiones colocadas por la libertad ontológica son cuestiones relativas a la relación hombre-naturaleza, la libertad social se centra en la discusión de la relación individuo-poder ${ }^{75}$.

\subsection{Tercer ajuste: ajuste normativo}

El tercer ajuste es el ajuste normativo. Para aclararlo, seguimos una vez más a VON WRIGHT. De acuerdo con el postulado asumido en «The Varieties of Goodness», según el cual la moralidad de una acción realizada por una persona es medida en función de cómo afecta el bienestar de sus congéneres, VON WRIGHT destaca que las acciones humanas, aunque estén sujetas a determinantes y constricciones, conciernen a las motivaciones humanas y a las presiones sociales, no a las determinaciones causales ${ }^{76}$. Es más, no habiendo ningún espacio para la acción, pensar en libertad tendría poco o ningún sentido físico ${ }^{77}$.

Para que pueda comprenderse bien este punto es importante destacar la diferencia que VON WRIGHT resalta entre el campo perteneciente al determinismo y el campo perteneciente a la libertad ${ }^{78}$.

Según VON WRIGHT, el campo del determinismo es el espacio de lo natural y su estudio es realizado por las ciencias de la naturaleza; no obstante, el campo de la libertad es el espacio de lo humano y de lo social, y su estudio corresponde a las ciencias sociales. De ahí la diferenciación entre la naturaleza física por un lado y, por el otro, la intencionalidad. Aunque causalidad (parte del mundo físico) y libertad (parte del mundo social) se crucen, ellas constituyen categorías diferentes.

En otras palabras, para VON WRIGHT las acciones humanas están adscritas a las razones, y como tales, no están previamente determinadas. De este modo, un mensaje del

${ }^{74}$ Este aspecto hace comprensible la afirmación de STRAwSON (en STRAWSON, 1982) según la cual: «A sustained objectivity of inter-personal attitude, and the buman isolation which that would entail, does not seem to be something of which human beings would be capable, even if some general truth were a theoretical ground for it». Para este punto, vid. también NINO, 1987: 106-107; NiNO, 1980: 374-380.

75 Para esta relación con el campo político, PetTit, 2001.

76 VON WRIGHT, 1963: 189-190.

77 VON WRIGHT, 1984: 109-112.

78 VON WRIGHT, 1974: 113-114. 
cerebro a mi cuerpo «no causa» (a no ser en un sentido puramente metafórico) una acción, sino que activa el deseo del agente de emprenderla. El camino de este «mensaje» es puramente mental-químico; lo cognitivo y lo informacional no tienen en él su lugar.

Siendo así, VON WRIGHT asocia la noción de libertad con las capacidades humanas. Y, en este caso, decir que alguien actuó en el mundo libremente es lo mismo que determinar que él, el agente, podría haber actuado de otra manera. ¿Pero qué es actuar de otra manera?

Según VON WRIGHT, cuando se afirma la posibilidad de actuar de otra manera se puede entender tres cosas distintas:

1. Que la acción, desde un punto de vista lógico, es una acción contingente, esto es, que describir una omisión no es una contradicción.

2. Que el agente tenía la capacidad de hacer (u omitir) la acción en cuestión.

3. Que el agente actuó como quiso porque actuó movido por una razón.

Se debe advertir que mientras el primer punto es formal, el segundo es empírico porque expresa potencialidad de acción no realizada de hecho (pero todas posibles); finalmente, el tercer punto expresa la autodeterminación del agente. Por tanto, «posibilidades lógicas», «capacidades» y «razón» son los elementos constitutivos de la libertad para VON WRIGHT.

La suma de todo esto es que si el agente tuviese otra razón, habría actuado de otra manera. Por tanto, cuantas más razones un agente tenga, más libre será, porque su libertad se amplía a medida que sus elecciones se dan por las posibilidades que visualiza en su actuar con esas mismas razones ${ }^{79}$. Dicho de otro modo, cuanta más capacidad deliberativa tenga el agente, más libre será, y de ahí su dependencia con la instrucción, la educación, etcétera.

Así, el agente racional ideal de VON WRIGHT es aquel que decide actuar tomando en atención los fines ${ }^{80}$. Esta es la «dimensión de la libertad» de VON WRIGHT, dimensión que presenta un fuerte enlace con la realidad concreta de los individuos ${ }^{81}$. Es por ello que la idea de libertad humana no es la misma para todas las sociedades o culturas, siendo un desatino pensar en una «esencia de la libertad» (una ontología) que será revelada. La libertad griega no es la misma que la libertad socialista; ésta no es la misma que la de un país fundamentalista, ni siquiera la de un país democrático liberal: las aspiraciones, las capacidades y las razones de las que cada uno de los agentes en estas épocas dispone no son las mismas. No existe una noción de libertad que escape a la historia y a la cultura.

VON WRIGHT, al entender la «libertad» como la capacidad de hacer o realizar cosas

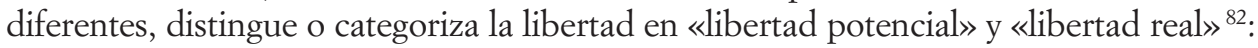

\footnotetext{
79 Por tanto, en términos básicos, se puede decir que una razón es un «deseo» y una «creencia» respecto de cómo es posible satisfacerlo. Para ello, vid. MoYA, 1997: 64

${ }_{80}$ Además, este es el punto de la «hipótesis de trabajo» de CARDOZO: en las relaciones sociales las personas actúan; para el derecho eso se traduce en tener condición de reflexionar sobre sus actos y entender lo que se hace.

${ }_{81}$ En este sentido, no descansa en impulsos naturales innatos. Para un análisis de los aspectos morales de este punto, ibid., 60.

82 VON WRIGHT, 1984: 116.
} 
1. «Libertad potencial» es esta capacidad genérica.

2. «Libertad real» es la capacidad del agente de realizar u omitir acciones concretas.

Por eso ésta depende del número de restricciones que afecten a su libertad potencial. Tales restricciones son «internas» y «externas»:

2.1. Por «restricciones externas» VON WRIGHT designa las restricciones de naturaleza física que impiden o imposibilitan a alguien hacer algo, así como las restricciones normativas de carácter legal, moral y otros órdenes que componen el mundo social del agente $^{83}$.

2.2. «Restricciones internas», que pueden ser tanto a) «psicológicas» como b) «normativas».

En el primer nivel $a$ ), están situados tanto los deseos como el temor y el odio; en el segundo nivel $b$ ), las normas internalizadas por el agente y que regulan su vida. Tanto las restricciones internas como las externas pueden ser tales que impiden que se considere un agente libre y responsable.

Así, la conclusión de VON WRIGHT es que para que se pueda considerar una acción como libre, o que un agente haya actuado libremente, ésta debe obedecer a las razones del agente, por más que la misma esté limitada potencialmente. Este posicionamiento teórico, consistente en comprender las limitaciones institucionales del actuar humano y sus consecuencias en relación con sus instituciones, es el que permite analizar la libertad como una acción controlable por deliberaciones humanas individuales y regidas por reglas socialmente establecidas. Como tales, esas reglas son contingentes y, por tanto, variables entre las distintas sociedades. A estos estímulos externos VON WRIGHT se refiere como «presión normativa» ${ }^{84}$.

Las consecuencias de esa presión normativa varían de acuerdo a la regla institucional en juego, es decir, en función de su carácter moral o jurídico. Pero, de todos modos, lo que importa es que esta determinante externa, poco a poco, es asimilada por los destinatarios de las normas, volviéndose así una determinante interna. Esto produce que se reduzca paulatinamente la necesidad de intervención externa. A este paso, de las determinaciones externas a las internas, nuestro autor le atribuye el nombre de «internalización» ${ }^{85}$.

Por tanto, lo que vON WRight está afirmando es que, dada la multiplicidad de empleos del vocablo «libertad», se han confundido las relaciones entre individuo y naturaleza por un lado y, por el otro, entre individuo y sociedad; una relación que se establece entre individuo y poder, esto significa, individuo y autoridad. Esto se debe a que mientras las «leyes» del Estado son modalidades deónticas (estatuyen lo obligatorio, lo permitido, lo prohibido), las «leyes» físicas son modalidades aléticas (expresan lo que es posible, imposible y necesario) ${ }^{86}$. De esta manera, no sólo VON WRIGHT resuelve el problema del determinismo causal, sino también el indeterminismo social: las acciones humanas están sujetas a razones y a constricciones socialmente establecidas.

${ }^{83}$ Ibid., 117.

84 VON WRIGHT, 1976: 419.

85 Ibid., 419-420.

86 KIEFER, 1994. 
Y es a partir de esos datos que VON WRIGHT sostiene la tesis que aquí será reconocida con la designación de «tesis VON WRIGHT»:

Todos los conceptos usados para describir y explicar las acciones de un hombre — como motivos, razones, intenciones, elecciones, deliberaciones, etc.- están relacionados con la idea de «libertad». Negar que un agente sea libre equivale a cometer una contradicción en los términos. El «misterio» de la libertad, si existe tal cosa, es el «misterio» del hecho de que somos agentes de acciones ${ }^{87}$.

\section{CONCLUSIÓN: SOBRE LOS LÍMITES DEL NEURODERECHO}

Como se ha destacado al inicio, la hipótesis de la libertad es una hipótesis de trabajo en el contexto jurídico, al menos, estadounidense ${ }^{88}$. Pero, aunque los tribunales americanos asuman la libertad, ellos también han admitido situaciones en las cuales el agente parece sufrir algún tipo de determinación, tales como en los casos de enfermedad mental, crímenes cometidos por adolescentes, y problemas cerebrales de varios tipos $^{89}$.

Para acomodar esas inconsistencias ${ }^{90}$, una de las posibilidades es asumir la posición del autoengaño de la libertad, basándose en los beneficios prácticos de esa amplia aceptación. De ese modo, los ajustes hechos en sede judicial se podrían comprender como acomodaciones de esa ilusión de la libertad, nada más ${ }^{91}$. Según lo que entendemos, ese malabarismo puede ser evitado con algunas aclaraciones. Aclaraciones que

87 VON WRIGHT, 1951: 78-79.

88 Steward Machine Co. vs. Davis, 301 EE.UU. 548, 590 (1937). Vid. también Bethea vs. Estados Unidos, 365 A. 2d 64, 83 n. 39 (DC 1976) (mientras que la teoría determinista de la conducta «tiene algunos seguidores, la idea de que la conducta de una persona es una simple función de las fuerzas extrínsecas y de las circunstancias, sobre las que no tiene control, es una contradicción inaceptable del concepto de libre albedrío, que es la condición sine qua non de nuestro sistema de justicia penal»); Kwosek vs. State, 100 NW2d 339, 345 (Wisc. 1960) («el libre albedrío es un atributo inherente que se encuentra dentro del ser humano, el poder de autocontrol»); Vid. United States vs. Grayson, 438 EE.UU. 41, 52 (1978); Morissette vs. Estados Unidos, 342 EE.UU. 246, 250 (1952); Los abogados en todos los países responderán «si no existe ninguna razón, ni elección, ni voluntad, entonces no puede haber ninguna ley...». Blocker vs. United States, 288 F.2d 853, 867-868 (D.C. Cir. 1961); Steward Machine Co. vs. Davis, 301 EE.UU. 548, 590 (1937), vid. también Bethea vs. United States, 365 A. 2d 64, 83 n. 39 (DC 1976), «Para la protección de la sociedad la ley acepta la tesis de que todos los hombres están investidos de libre albedrío...». State vs. Sikora, 210 A.2d 193, 202 (N.J. 1965); «Nuestra jurisprudencia... en última instancia se basa en la premisa de la libertad de la voluntad. Esto no debe ser visto como un ejercicio en el discurso filosófico, sino como una función gubernamental de la ética y la obligación, que tiene en cuenta que un sistema de premios y castigos en sí es parte del entorno que influye y determina la conducta humana», United States vs. Brawner, 471 F. 2 d 969, 995 (D.C. Cir. 1972).

89 De todos modos, los tribunales americanos no aceptan cualquier factor como suficiente para interferir en las acciones humanas. Schwarzenegger vs. Entertainment Merchants Association, 08-1448. Schwarzenegger vs. Entertainment Merchants Association, 08-1448.

90 Esto es lo que se puede leer en un leading case: «[...] el fundamento de la ley en la voluntad humana y en el libre albedrío contrasta con los sistemas de creencias de algunos psicólogos ... que creen en el determinismo...». United States Court of Appeals, Eleventh Circuit, Weeks vs. Jones, 52 F.3d 1559, 1567 n. 10 (11th Cir. 1995); «Es una negación de toda nuestra tradición decir que toda transgresión social es el resultado de una enfermedad», Supreme Court of Appeals of West Virginia, State ex rel. D.D.H. vs. Dostert, 269 S.E.2d 401.

91 Vid. ítem V de este estudio. NiNO, con respecto al problema filosófico de la libertad, llega a afirmar que el aspecto destructivo de las posiciones en disputa, renuncian a la libre voluntad, pero no colocan nada en su lugar. NiNO, 1980: cap. V. 
resultan relevantes en el discurso jurídico dado que los sistemas normativos pueden admitir estudios neurocientíficos como pruebas periciales ${ }^{92}$.

En primer lugar, decir que la neurociencia consigue explicar el mecanismo de funcionamiento del cerebro (o intenta explicar cómo funciona el cerebro) es una cosa; la otra, es decir que un determinado resultado es inevitable, de manera que no se puede confundir la determinación con el fatalismo ${ }^{93}$. Incluso porque no todos los agentes con un problema en el lóbulo frontal son criminales o cometen delitos.

En segundo lugar, algunos neurocientíficos sostienen que en caso de que se pueda identificar el origen causal determinante de los comportamientos humanos, deberían extraerse consecuencias jurídicas, tales como: «Todos deben ser tratados, pero no castigados». Aunque este argumento suene persuasivo a primera vista, contiene claramente un salto lógico, al derivar de un «ser» (la descripción del comportamiento determinado) un «deber ser» (la medida de tratamiento coactivo u otra medida cualquiera) ${ }^{94}$. Esa relación entre hecho y consecuencia depende del posicionamiento jurídico-político legislativo ${ }^{95}$.

En este sentido, desde la mirada relativa al proyecto descriptivo no es posible inferir resultados prácticos relacionados con el segundo proyecto (proyecto sustancial) y con el tercer proyecto (proyecto normativo) sin alguna premisa adicional ${ }^{96}$. Para que se establezca una comunicación entre ellos, es necesaria alguna consideración en términos ético-morales o políticos ${ }^{97}$.

En tercer lugar, afirmar que alguien actuó exclusivamente en razón de cierto mecanismo cerebral es también problemático porque como somos agentes biológicos siempre será posible señalar algún mecanismo cerebral involucrado en nuestras acciones ${ }^{98}$. En otras palabras, los cerebros pueden funcionar con mecanismos automáticos, pero la «libertad» que importa se sitúa en la interacción social ${ }^{99}$. Como ya se dijo alguna vez, «los cerebros no cometen delitos, las personas sí» ${ }^{100}$.

92 Molina, 2000: 272-274; DwORKIN, 2011: 232-233.

93 RuSSELl, 2000.

94 Más sensatas son las propuestas posibles de mejoría del sistema jurídico en determinadas situaciones de patología y, no su derivación necesaria, GrEELY, 2008. De todos modos, en este caso, son las decisiones de índole político-legislativa las que promoverían estas modificaciones, no la neurociencia. Es decir, el impacto de la neurociencia en relación con las leyes puede ser indirecto, jamás directo. El cambio en las leyes depende de decisiones político-institucionales y del juego de representación política. El discurso aquí es de iure conditio y de iure condendo, NiNO, 1987: 108.

95 A veces eso ocurre como apertura normativa para reducciones de la pena. En el caso decidido en la Corte de Assisi y de Apelación de Trieste (Italia), la Corte aceptó la opinión pericial que demostró propensión genética a la violencia con vistas a la reducción de la sanción. CAPRA, 2000; TSOUDEROS, 2010.

96 Agradezco al grupo de investigadores de la Università Bocconi por cuestionar este aspecto, posibilitándome acrecentar ahora este párrafo.

97 Por tanto, aquí no se están cuestionando los descubrimientos neurocientíficos; lo que se está haciendo es presentar un posible punto de diálogo entre los estudios neurocientíficos y la práctica jurídica actual. De todos modos, se debe notar que el emprendimiento neurocientífico implica una «naturalización» del ser humano en el sentido de no considerarlo un ser «especial» o «apartado» de las fuerzas de la naturaleza, como la causalidad y el determinismo. Para este aspecto, SCHAEFfER, 2009: cap. I. Para un abordaje ético del tema, DWORKIN, 2011.

98 MORSE, 2006.

99 Molina, 2000: 233.

100 MorSe, 2000: 252. 
En cuarto lugar, se debe consignar que los estándares de aceptabilidad entre las afirmaciones neurocientíficas y jurídicas pueden diferir, de modo que a veces el estándar jurídico puede ser menos exigente que el estándar científico para establecer sus conclusiones y consecuencias ${ }^{101}$ en sede judicial y, otras veces, puede, el campo jurídico, incluso no admitir los estándares científicos y sus conclusiones en atención a algún valor que pretende proteger. Este aspecto es relevante, sobre todo, cuando se trata de fMRI. Esto se debe a que es legítimo preguntar si un ser humano puede ser reducido a un signo (y, por tanto, al objeto) para efectos de lectura y conclusiones jurídicas. Además, se debe pensar en el derecho a la privacidad (privacy) en relación con las técnicas de mind-reading y en el problema de los incidental-findings.

Finalmente, la aclaración anterior atrae la atención hacia un aspecto importante presente entre los datos presentados por los neurocientíficos: la distinción entre el dato neurocientífico y su interpretación en el campo judicial.

\section{REFERENCIAS BIBLIOGRÁFICAS}

Austin, J. L., 1955: «A Plea for Excuses», Proceedings of the Aristotelian Society, vol. 24.

BAYÓN, J. C., 1991: La normatividad del derecho: Deber jurídico y razones para la acción, Madrid: Centro de Estudios Constitucionales.

BoвBIo, N., 1977: Le sanzioni positive, Milano: Comunità.

Burns, J. M., y SwerDlow, R. H., 2003: «Right Orbitofrontal Tumor with Pedophilia Symptom and Constructional Apraxia Sign», Archives of Neurology, vol. 60.

CAPRA, G., 2000: «Le neuroscienze e la genetica molecolare nella valutazione della capacità di intendere e di volere (Commento alla sentenza della Corte d'Assise d'Appello di Trieste, n. 5/2009 del 18/09/2009)», Psicologia e Giustizia, vol. XI (1).

Chomsky, N., 1975: Reflections on Language, New York: Pantheon Books.

Chorvat, T., y MacCabe, K., 2004: «The Brain and the Law», The Royal Society.

DAvidSon, D., 1995: «Libertad para actuar», en Ensayos sobre Acciones y Sucesos, México: Crítica.

De CARO, M., 1998: «Determinismo e libero arbitrio: Rinascita di una controversia», en Caso, Necessità, Libertà, Napoli: CIEN.

Dworkin, R., 2011: Justice for Hedgehogs, London: Harvard University Press.

Eagleman, D., 2011: «The Brain on Trial», The Atlantic Magazine.

ElLIS, H. D., y LewIS, M. B., 2001: «Capgrass Delusion: A Window on Face Recognition», Trends in Cognitive Sciences, vol. 5 (4).

FERRAZ Jr., T. S., 1980: «Liberdade e Respondabilidade Penal», Seqüência.

FrankFurT, H., 1971: «Freedom of the Will and the Concept of a Person», The Journal of Philosophy, vol. 68 (1).

- 1991: «The Faintest Passion», en Necessity, Volition, and Love, Cambridge: Cambridge University Press.

Gazzaniga, M. S., y Steven, M. S., 2005: «Neuroscience and the Law», Scientific American.

Goodenough, O. R., y PreHn, K., 2004: «A Neuroscientific Approach to Normative Judgement in Law and Justice», The Royal Society. 
Greely, H. T., 2008: «Neuroscience and Criminal Justice: Not Responsibility but Treatment», Kansas Law Review, vol. 56.

HaRT, H. L.A., 1958: «Legal Responsibility and Excuses», vol. Determinism and freedom in the age of modern science.

Hotz, R. L., 2009: «The Brain, Your Honor, Will Take the Witness Stand (Researchers Probe How the Mind Determines Crime and Punishment, But Science isn't Beyond a Reasonable Doubt)», The Wall Street Journal.

Hughes, V., 2010: «Head Case», Nature, vol. 464 (18).

KaHAne, H., 1983: Thinking about Basic Beliefs, Belmond: Wadsworth.

KANE, R., 1996: The Significance of Free Will, New York: Oxford University Press.

KELSEN, H., 1957: «The Law as a Specific Social Technique», en What is Justice? (Justice, Law, and Politics in the Mirror of Science), Los Angeles: University of California Press.

KERSHAW, S., 2002: «The Hunt for Sniper: The Dead. Escaping the Grip of Cancer, Only to Die at a Sniper's Hand», New York Times.

KIEFER, F., 1994: «Modality», The encyclopedia of language and linguistics.

KISTLER, M., 1999: Causation and Laws of Nature, New York: Routledge.

Lane, Ch., 2005: «5-4 Supreme Court Abolishes Juvenile Executions», The Washington Post.

LEWIS, D., 1982: «Are we Free to Break the Law?», Theoria, vol. 47 (3).

LIPTAK, A., 2005: «Supreme Court rule on Executing Young Killers», The New York Times.

— 2010: «Justices Limit Life Sentences for Juveniles», New York Times.

LOCKE, J., 2000: «Ensayo sobre el entendimiento humano».

MacGinn, C., 1999: The Misterious Flame, New York: Basic Books.

MolinA, F., 2000: «Presupuestos de responsabilidad jurídica (análisis de la relación entre libertad y responsabilidad)», ADPCP, vol. LIII.

Morse, S. J., 2000: «Rationality and Responsibility», Southern California Law Review, vol. 74.

- 2006: «Brain Overclaim Syndrome and Criminal Responsibility: A Diagnostic Note», Obio State Journal of Criminal Law, vol. 3.

Moya, C., 1997: «Libertad, responsabilidad y razones morales», Isegoria, vol. 17.

Nagel, Th., 1996: Una visión de ningún lugar, México: Fondo de Cultura Económica.

Nichols, S., 2004: «The Folk Psychology of Free Will: Fits and Starts», Mind E Language, vol. 19 (5).

NinO, C. S., 1980: Los límites de la responsabilidad penal: Una teoría liberal del delito, Buenos Aires: Astrea.

- 1987: Introducción a la filosofía de la acción bumana, Buenos Aires: Editorial Universitaria de Buenos Aires.

O'Connor, T., 1993a: «Alternative Possibilities and Responsibility», Southern Journal of Philosophy, vol. 31.

- 1993b: «Indeterminism and Free Agency: Three Recent Views», Philosophy and Phenomenological Research, vol. 53.

- 2000: Persons and Causes: The Metaphisics of Free Will, New York: Oxford University Press.

Overbye, D., 2007: «Free Will: Now You Have It, Now You Don't», The New York Times.

PetTit, Ph., 2001: A Theory of Freedom: From the Psychology to the Politics Agency, Polity Press.

Rosen, J., 2007: «The brain on the stand: How neuroscience is transforming the legal system», The New York Times Magazine. 
Ross, A., 1975: On Guilt, Responsibility and Punishment, University of California Press, Los Angeles.

Russell, P., 2000: Compatibilist-Fatalism, Utrecht: Kluwer.

SAuL, S., 2008: «"The Ambien Case” - Some Sleeping Pill Users Range far Beyond Bed», The New York Times.

SCHAEFFER, J.-M., 2009: El fin de la excepción bumana, México: Fondo de Cultura Económica.

SCHauer, F., 2010a: «Can Bad Science be Good Evidence?», Cornell Law Review, vol. 95.

- 2010b: «Neuroscience, Lie-Detection, And the Law: Contrary to the Prevailing View, the Suitability of Brain-Based Lie-Detection for Courtroom or Forensic Use Should Be Determined According to Legal and Not Scientific Standards», Trends in Cognitive Sciences, vol. 14 (3).

Schiffer, B.; Peschel, Th.; Paul, Th.; Gizewski, E.; Forsting, M.; Leygraf, N.; SchedLOWSKI, M., y KRUEGER, T. H. C., 2007: «Structural Brain Abnormalities in the Frontostrital System and Cerebellum in Pedophilia», Journal of Psychiatric Research, vol. 41 (9).

SCHLICK, M., 1939: Problems of Ethics, New York: Prentice-Hall.

Sinnot-Armstrong, W.; Roskies, A.; Brown, T., y Murphy, E., 2008: «Brain Images as Legal Evidence», Episteme.

SmILANSKy, S., 2000a: Free Will and Illusion, Oxford: Oxford University Press.

— 2000b: «Free will: From nature to illusion», Meeting of Aristotelian Society.

Sober, E., 2004: Core Questions in Philosophy: A Text with Readings, New York: Prentice Hall.

STRAWSON, P. F., 1982: «Freedom and Resentment», en Free Will, Oxford: Oxford University Press.

Tost, H.; Vollmert, Ch.; Brassen, S.; SChmitt, A.; Dressing, H., y Braus, D. F., 2004: «Pedophilia: Neuropsychological Evidence Encouraging a Brain Network Perspective», Medical Hypothesis, vol. 63 (3).

Tsouderos, T., 2010: «Exploring inks Between Genes, Violence, Environment», Chicago Tribune.

Van InWagen, P., 1983: An Essay on Free Will, Oxford: Oxford University Press.

Von Wright, G. H., 1951: Essays on Modal Logic, Amsterdam: North-Holland.

- 1963: The Varieties of Goodness, London: Routledge \& Keagan.

- 1974: «Causality and Determinism», Wordbridge Lectures (October and November of 1972).

- 1976: «Determinism and the Study of Man», en Essay on Explanation and Understanding, Kluwer: Dordrecht.

- 1984: «Of Human Freedom», The Tanner Lectures of Human Values.

Weatherford, R. C., 2005: «Determinism», The Oxford Companion to Philosophy.

Wolf, S., 1981: «The Importance of Free Will», Mind, vol. 90. 